\title{
The ventilatory response to hypoxia: how much is good for a mountaineer?
}

\author{
J.S. Milledge \\ Division of Anaesthesia, Clinical Research Centre, Northwick Park Hospital, Harrow HA1 3UJ., UK.
}

\begin{abstract}
Summary: Methods for measuring the ventilatory response to hypoxia (HVR) are reviewed. The criteria for success as a high altitude mountaineer are defined as freedom from acute mountain sickness (AMS) and ability to perform well at extreme altitude.

The evidence for a brisk HVR being protective against AMS and associated with successful high altitude performance is reviewed. The contrary evidence of blunted HVR in high altitude residence and some elite climbers is discussed. The effect of a brisk HVR in producing periodic breathing when asleep at altitude is noted.

It seems that there is an optimum HVR for different circumstances and peoples. A brisk HVR is a benefit in lowlanders going to altitude for the first time whereas a blunted HVR is appropriate for high altitude residents and possibly for very experienced elite climbers.
\end{abstract}

The ventilatory response to hypoxia (HVR) is the increase in minute ventilation induced by hypoxia. As $\mathrm{PO}_{2}$ (inspired) is reduced, there is little increase in ventilation at first, then ventilation increases exponentially. This non-linear relationship has meant that different workers have used different ways of expressing HVR.

The Oxford School' properly described the hyperbola in terms of its 2 asymptotes and a shape parameter they called A. The Denver group ${ }^{2}$ fixed the $\mathrm{PO}_{2}$ asymptote at $32 \mathrm{~mm} \mathrm{Hg}$ (rather arbitarily, I feel), so only allowing A to vary. Severinghaus et al. ${ }^{3}$ calculated the response at only two $\mathrm{PO}_{2}$ levels, quoting the increase in ventilation on shifting from high $\mathrm{PO}_{2}$ $(>150)$ to $40 \mathrm{~mm} \mathrm{Hg}$, the ' $V 40$ ', whilst the McMaster group ${ }^{4}$ using an ear oximeter to measure oxygen saturation, showed that the increase in ventilation was linearly related to $\mathrm{Sa}, \mathrm{O}_{2}$ and expressed HVR as $V /$ $\mathrm{Sa}, \mathrm{O}_{2}$. Others have used single or a few breaths of low oxygen mixture, or high oxygen on a background of hypoxia and derived yet other indices of HVR.

However, I am not concerned in this paper with discussing the pros and cons of the various approaches. Studies must always include their own controls and so are perfectly valid but obviously one cannot compare one study with another where different expressions are used, except in a qualitative way. Fortunately, differences are often so marked that this

Correspondence: J.S. Milledge M.D., F.R.C.P. can be done using terms such as 'brisk' or 'blunted' responses.

What criteria are we to use for what is 'good' for a mountaineer? I have used two criteria: (1) ability to acclimatize rapidly, including freedom from acute mountain sickness (AMS) and (2) the ability to perform well at extreme altitudes.

These two abilities usually go together but there may be individuals who have trouble acclimatizing initially then go well very high up, and others who, though they have no trouble on arrival at high altitude, are unable to perform at extreme altitudes. But such people are the exception and most Himalayan climbers who perform prodigiously at extreme altitude have the ability also to ascend rapidly from sea level to $5000-6000 \mathrm{~m}$ with no symptoms of AMS. For the purpose of this paper, then, I will use freedom from AMS and ability to perform well at extreme altitudes as evidence of success in mountaineering.

It would seem common sense that a brisk HVR must be beneficial to a mountaineer. As he ascends and the inspired $\mathrm{PO}_{2}$ falls the falling $\mathrm{Pa}, \mathrm{O}_{2}$ triggers his response to increase his ventilation, lower his $\mathrm{PCO}_{2}$ and restore to some extent his $\mathrm{Pa}, \mathrm{O}_{2}$ towards normal. However, before accepting this view we would like to confirm that a high HVR is beneficial and actually there are a number of observations that run counter to this simple view. I propose to set out the evidence as a sort of internal debate, first for, then against, the proposition that a brisk HVR is good for a mountaineer. 


\section{Advantages of a brisk HVR}

\section{Evidence that a brisk $H V R$ protects against AMS}

Lakshminarayan \& Pierson ${ }^{5}$ showed that a subject who had recurrent high altitude pulmonary oedema had blunted HVR, but this in only one subject. Hu et $a l .{ }^{6}$ showed that six good acclimatizers had brisk HVR while four poor acclimatizers had blunted responses. Perhaps the most convincing evidence comes from Hackett $e t$ al. ${ }^{7}$ because they worked with large numbers of subjects (42 trekkers) and the study was conducted in the real life context of a trek to Everest Camp Base, although HVR was only inferred from changes in $\mathrm{Pa}, \mathrm{CO}_{2}$. They studied their subjects in Katmandu and again at Pherichi $(4,243 \mathrm{~m})$. They found that their subjects could be divided into groups by weight change. Those who lost more than $2 \%$ of their bodyweight, those who gained more than $2 \%$ and those whose weight was unchanged. Those who lost weight had very little AMS, the highest $\mathrm{O}_{2}$ saturation and the lowest $\mathrm{Pa}, \mathrm{CO}_{2}$, implying a high HVR, whilst those who gained weight, presumably by fluid retention had marked AMS, lower $\mathrm{Sa}, \mathrm{O}_{2}$ and a $\mathrm{Pa}, \mathrm{O}_{2}$ unchanged from Katmandu, implying blunted HVR. Those showing no weight change were intermediate in all these respects.

Finally, we could add the evidence from numerous trials of acetazolamide which certainly protects against AMS and has been shown to increase ventilation. It would seem most likely that these two observations are causally related. Acetazolamide achieved the same results on blood gases as a brisk HVR with the same good effect.

\section{HVR and performance at extreme altitude}

There has been very little work done on this subject. Schoene ${ }^{8}$ showed that 14 high altitude climbers had significantly higher HVR than 10 controls whilst 10 endurance runners had lower HVR, as had been shown by other workers previously e.g. Byrne-Quinn et al. ${ }^{9}$

During the 1981 American Research expedition to Everest, Shoene et al. ${ }^{10}$ extended this work, showing again that the HVR measured before and on the expedition correlated well with performance high on the mountain. We also showed that at high altitude the fall in $\mathrm{O}_{2}$ saturation on exercise was greater in subjects with a low HVR and least in those with a brisk response. Thus, subjects with a blunt HVR were not only more hypoxic at rest but had even greater hypoxia on exercise than brisk responders. This is because of the well-known correlation between HVR and exercise ventilatory response.

\section{Disadvantages of a brisk HVR}

\section{Peoples native to high altitude}

The earliest evidence that a brisk HVR may not always be an advantage came from the almost simultaneouso work of Severinghaus et al. ${ }^{3}$ and ourselves ${ }^{11}$ showingo blunted HVR in Andean and Himalayan high altitude ${ }^{\bar{n}}$. residents respectively. One might argue that the blunt $-\frac{\mathbb{D}}{\Omega}$ ing of HVR in these peoples is a maladaptation, ando this was Severinghaus' view, based partly on his? finding that in Andean natives with chronic mountain $\overrightarrow{0}$ sickness, the HVR was even more attenuated. $\overrightarrow{\vec{\omega}}$ However, if one has climbed with Sherpas at altitude, $\stackrel{\omega}{\sigma}$ it is hard to sustain the view that they are in any waye maladapted to that environment. They may be ven-3. tilating less than the lowland climbers but they usuallyo. carry more and climb faster. I agree that the extreme blunting of HVR in chronic mountain sickness may contribute to that condition, making for more- profound hypoxia and hypercapnia just as it does ine our own 'blue bloaters' with chronic bronchitis, but to응 suggest by extension that the more modest reductionin HVR in other highlanders is therefore maladapta-? tion is equivalent to suggesting that endurance runners with reduced HVR are maladapted. I would argue that ${ }^{\supset}$ for Sherpas, fit Andean highlanders and endurangeco runners a reduced HVR is appropriate and benefici解.

It might be argued that this is a racial (or genet attribute. But the blunting of HVR is seen Caucasians and is dependent upon the age of people born at altitude ${ }^{2}$ requiring 10-30 years to develop. Lahiri et al ${ }^{12}$ suggest that it develops more quickly the higher the altitude. Does the HVR become blunted in lowlanders going and staying at high altitude? Earlyọ studies ${ }^{13}$ showed no evidence of this over 5-7 years at about $4,000 \mathrm{~m}$ but with longer term residence, even at $3,000 \mathrm{~m}$ there is some blunting of response. ${ }^{2}$

\section{Climbers with blunted HVR}

We studied the four elite climbers who formed the climbing team on our expedition to Mount Kongur? and compared these with four members of the scientific party, mountaineers of more modest ${ }^{2}$ achievement. ${ }^{14}$ We found the climbers to have less brisk HVR than the scientists.

Recently Schoene et al. ${ }^{15}$ have reported on one of the or climbers to first reach the summit of Everest without supplementary oxygen. He had blunted HVR. SoN despite the evidence from his earlier work, the evidence $\omega$ from actual extreme altitude climbers is inconclusive.

\section{Sleep studies}

So far we have concentrated only on subjects when awake but a good percentage of time is spent asleep. 
AMS is often worse in the mornings and hypoxia is often worse at night. How does HVR affect sleep? One might suppose that those with a higher HVR would be less hypoxic than those with blunted HVR during sleep as well as when awake, but this may not be the case. Lahiri et al., ${ }^{16}$ also on the American Medical Research expedition to Everest, have shown what was previously suspected, that a brisk HVR is necessary to produce periodic breathing. This, in turn, results in profound hypoxia during the periods of apnoea. It may well be that repeated short periods of severe hypoxia are more detrimental than low average $\mathrm{PO}_{2}$. Thus the subject with high HVR and periodic breathing could be worse off than a subject with a rather lower HVR who thereby avoids periodic breathing. Note that in this respect acetazolamide therapy differs from the effect of a brisk HVR in that subjects on acetazolamide are less prone to periodic breathing. ${ }^{17}$

\section{Conclusion}

I suggest that under various conditions, different HVRs are optimum. Responses much above or below this optimum would be disadvantageous. I think we are fairly safe in concluding that for a lowlander going to high altitude for the first time, a brisk HVR is an advantage. With a low HVR he would be more likely to suffer from AMS. Possibly, with a very high HVR he would have more periodic breathing starting at

\section{References}

1. Lloyd, B.B., Jukes, M.G.M. \& Cunningham, D.J.C. The relation between alveolar oxygen pressure and the respiratory response to carbon dioxide in man. $Q J$ Exp Physiol 1958, 43: 214-227.

2. Weill, J.V., Byrne-Quinn, E., Sodal, I.E., Filley, G.F. \& Grover, R.F. Acquired attenuation of chemoreceptor function in chronically hypoxic man at high altitude. $J$ Clin Invest 1971, 50: 186-195.

3. Severinghaus, J.W., Bainton, C.R. \& Carcelen, A. Respiratory insensitivity to hypoxia in chronically hypoxic man. Resp Physiol 1966, 1: 308-334.

4. Rebuck, A.S. \& Campbell, E.J.M. A clinical method for assessing the ventilatory response to hypoxia. Am Rev Respir Dis 1974, 109; 345-350.

5. Lakshminarayan S. \& Pierson D.J. Recurrent high altitude pulmonary edema with blunted chemosensitivity. Am Rev Respir Dis 1975, 111: 869-872.

6. Hu, S.T., Huang, S.Y., Chu, S.C. \& Pa, C.F. Chemoreflex ventilatory responses at sea level in subjects with past history of good acclimatization and severe acute mountain sickness. In: Brendel, W. \& Zink, R.A. (eds) High Altitude Physiology and Medicine. Springer Verlag, New York, Heidelberg, Berlin, 1982, pp. 28-32.

7. Hackett, P.H., Rennie, D., Hofmeister, S.E., Grover, R.F., Grover, E.B. \& Reeves, J.T. Fluid retention lower altitude than his companions and he might be more dyspnoeic on exertion.

In natives living at high altitude I am convinced that their blunted HVR is advantageous. I can only assume that adaptations over years and decades allow them to tolerate $\mathrm{Pa}, \mathrm{O}_{2}$ lower than lowlanders. For instance, they may have a richer capillary network and thus a smaller intercapillary distance, at least in vital organs such as brain, heart and working muscles. There may be intracellular enzyme changes resulting in tissue adaptation. If this is the case, the high altitude natives can dispense with a brisk HVR which would give them an unnecessarily high ventilation and would waste energy. A low HVR is therefore appropriate for them and has the advantage of giving them better sleep with no periodic breathing.

In looking for our 'Olympic Gold Medallist' high altitude climbers we must remember that this is an endurance sport and at low altitude a blunted HVR is apparently an advantage. Perhaps repeated trips to extreme altitude and, if possible, residence at modest alititude, for instance in the Alps or Colorado, may result in adaptations similar to those of Sherpas or Andean natives and, like them, allow lower $\mathrm{Pa}, \mathrm{O}_{2}$ to be tolerated. Therefore, again, in the very experienced Himalayan climber, a rather lower HVR would be appropriate.

Clearly the debate is not concluded. I hope these observations may help form the right questions which further studies can be designed to answer.

and relative hypoventilation in acute mountain sickness. Respiration 1982, 43: $321-329$.

8. Schoene, R.B. Control of ventilation in climbers to extreme altitude. J Appl Physiol 1982, 53: 806-890.

9. Byrne-Quinn, E., Weil, J.V., Sodal, I.E., Filley, G.F. \& Grover, R.F. Ventilatory control in the athlete. J Appl Physiol 1971, 30: 91-98.

10. Schoene, R.B., Lahiri, S., Hackett, P.H. et al. Relationship of hypoxic ventilatory response to exercise performance on Mount Everest 1984. J Appl Physiol 1984, 56: 1478-1483.

11. Milledge, J.S. \& Lahiri, S. Respiratory control in lowlanders and Sherpa highlanders. Respir Physiol 1967, 2: 310-322.

12. Lahiri, S., DeLaney, R.G., Brody, J.S., Simpser, M., Velasquez, T., Motoyama, E.K. \& Polgar, C. Relative role of environmental and genetic factors in respiratory adaptation to high altitude. Nature 1976, 261; 133-135.

13. Sørensen, S.C., \& Severinghaus, J.W. Respiratory sensitivity to acute hypoxia in man born at sea level living at high altitude. J Appl Physiol 1968, 25: 211-216.

14. Milledge, J.S., Ward, M.P., Williams, E.S. \& Clarke, C.R.A. Cardiorespiratory response to exercise in men repeatedly exposed to extreme altitude. J Appl Physiol 1983,55 ; $1379-1385$. 
15. Schoene, R.B., Hackett, P.H. \& Roach, R.C. Blunted hypoxic chemosensitivity at altitude and sea level in an elite high altitude climber. Proceedings Banff Symposium on Hypoxia and Cold (abstract) 1985.

16. Lahiri, S., Maret, K. \& Sherpa, M.G. Dependence of high altitude sleep apnoea on ventilatory sensitivity to hypoxia. Respir Physiol 1983, 52: 281-301.

17. Sutton, J.R., Houston, C.S., Mansell, A.L. et al. Effect of acetazolamide on hypoxemia during sleep at high altitude. $N$ Engl J Med 1979, 301: 1329-1331. 